\title{
BRAZUCA NEGÃO E SEBENTO
}

\author{
GODDARD, Jean-Christophe. \\ São Paulo: n-1 edições, 2017
}

Joca Wolff

(Universidade Federal de Santa Catarina)

Brésilien noir et crasseux est un livre du philosophe français Jean-Christophe Goddard. Brazuca negão e sebento é um outro livro: é um livro de João Ywarete Pyaguachu vertido ao brasileiro bárbaro por Karai Mirim - leia-se o tradutor amazônico Takashi Wakamatsu, com uma força de Fernando Scheibe e do próprio autor. Além disso, lê-se na ficha técnica deste livro bilíngue, feito com letras verdes e duas capas igualmente esverdeadas e monstruosas, cada uma de cabeça pra baixo em relação à outra, que: "Esta tradução foi discutida e aprimorada no quadro da 'Fabrique des Traducteurs' du Collège International des traducteurs littéraires de Arles". Mais além disso ainda, entendase que a edição de Brazuka, negão e sebento é pura luxúria de texto e design, tradução e transgressão, nas mãos da n-1 edições de Peter Pál Pelbart e Ricardo Muniz Fernandes, com prefácio de Eduardo Viveiros de Castro. Este, aliás, está implicado até o pescoço no que ele mesmo chamou de "texto pantofágico" e "antropojaguaromaquia fantástica” do filósofo francês especialista em Fichte, historiador da filosofia clássica alemã, professor da Universidade de Toulouse, que pirou na batatinha ao escrever "em estado de esquizo-estupefação criativa", como também disse Viveiros, não sobre o Brasil mas com o Brasil.

Emprego as gírias acima a partir do que a própria versão brazuca do ensaio estimula o leitor a pensar e a fazer com a língua portuguesa de Pindorama, estimulado por sua vez pelo próprio texto original (apenas algo mais contido). Porque, se o santo catatauesco baixou em Goddard - ou Pyaguachu, seu codinome índio -, ele baixou ainda mais fundo em Karai Mirim e sua tribo de deglutidores da pomposa e esbelta língua de René Descartes. Mas, no que diz respeito ao autor 
do ensaio, ele não apenas descobriu como rasgou o seu próprio Brasil profundo a partir de suas vozes e espíritos, malasartes e literaturas, com ênfase no sangue e no esperma extraíveis do Catatau de Paulo Leminski e dos escritos mais radicais de Clarice Lispector. Como se trata de um ensaio que toca fundo na ferida da escravidão e da miséria nacionais, um ano após a sua publicação ele se torna ainda mais agudo e incontornável. Isto porque estamos vivendo agora, 2019, o momento em que os que já sobreviviam no inferno estão indo literalmente para o beleléu. São eles os brazukas negões e sebentos do título reinventado apropriadamente pelo multitradutor, ao fazer transpirar e explodir as expressões depreciativas utilizadas por Goddard no título original com "brésilien noir et crasseux", em referência aos índios, quilombolas, mulheres, gays e todo tipo de marginal imaginável sob a ótica do fundamentalismo pentecostal-militar atualmente no poder.

Mas o brasileiro negro e sujo em questão é fruto de um pesadelo da filosofia europeia, branca e limpa. Mais precisamente, é fruto de um pesadelo de Benedictus de Spinoza registrado em carta de 1664, em que lhe surge a imagem de um escravo afro-brasileiro enquanto a aparição do próprio abominável inominável, nu e cru. Tendo recebido de presente (do amigo Viveiros) o Catatau leminskiano, além de Oswald, Clarice e o conceito de "diferOnça", Goddard trata de "desexplicar o Brasil" inspirado pelo que o jovem Leminski fizera em seu livro de estreia, de 1975: imaginar e alucinar a presença de Descartes, encarnando o próprio racionalismo moderno em chamas, na Recife de Mauricio de Nassau durante a invasão holandesa do século XVII, pondo em seu lugar um pensador de origem judaica e portuguesa Bento de Espinosa - convertido num respeitável pensador holandês - Benedictus ou Baruch de Spinoza. Assim, tomado pelo transe das mil-e-uma vozes do Catatau, entre outros transes - como o de Pierre Fatumbi Verger -, Goddard despiroca completamente no texto, já que o escreve de modo barroso e selvagem (de maneira inédita em seu trabalho, segundo confessou), invocando mil-e-uma vozes ele também, sem se preocupar com qualquer referência bibliográfica. Como disse o próprio Leminski em advertência aos leitores do Catatau, virem-se! É esse Espinosa negão, sebento e deleuziano que ele vai invocar em sua desleitura do Novo Mundo e que a Holanda, através da escravidão, do capital e da Companhia das Índias, buscava submeter. 
Lembro aqui, de passagem, que, também em 2017, a n-1 publicou Hegel e o Haiti de Susan Buck-Morss, em edição ilustrada e caprichada como a do livro de Goddard. Com pegadas completamente distintas, ambos os livros no entanto se referem de maneiras semelhantes à obnubilação afro-americana vivida por dois eminentes filósofos modernos. Já, no que se refere ao século XX, Goddard elege um alvo de grande importância para o Brasil e para a antropologia no mundo: Claude Lévi-Strauss. Dele diz e volta a dizer que não entendeu patavina do país: quem o fez, antes e bem, foi sua então esposa, Dina, que introduziu uma pedagogia etnográfica no Brasil sob os auspícios de Mário de Andrade. Mas, como se sabe, ela é inteiramente borrada das páginas dos Tristes Trópicos e das Saudades do Brasil. Neste ponto, Goddard e Viveiros se desentendem, ainda que de leve. Lembro também aqui, a propósito de Viveiros de Castro, que ele sente falta, no final de seu prefácio, de Sousândrade - "o Swedenborg inca que deskantianizou a metafísica hiperbórea com seu Tatuturema". Por meu lado, a ausência que se me apresenta no ensaio em relação à imagem do negro desnudo é a de uma passagem das Memórias do Cárcere de Graciliano Ramos, em que, no porão de navio em que são transportados "116 comunistas", admira, com estupefação e contra si mesmo, um negro suado e nu coçando o saco. 0 que igualmente me faz remeter ao final do primeiro romance de Graciliano, Caetés, de 1933, em que destacara a miséria dos índios à deriva pela cidade grande: a esta cena podemos contrapor a visão, se não otimista, ao menos produtiva ou criativa da figura do índio no pensamento deste escritor contemporâneo de Graciliano, Oswald de Andrade, o autor do "antropófago manifesto" que é exaltado em Brazuca negão e sebento a partir tanto da Tropicália quanto do perspectivismo ameríndio.

Hoje, infelizmente, a realidade indígena segundo Graciliano está se sobrepondo com rapidez àquela de Oswald. Mantenhamos o olho vivo numa e noutra. Uma das melhores formas de fazê-lo, contemplada no ensaio de Jean-Christophe Goddard, é prestando atenção, muita atenção, na narrativa da vida de Davi Kopenawa em A queda do céu - "uma palavra contra-antropológica porque só a palavra viva é contra-antropológica", como ele afirmou em outra parte. 0 nome do xamã Yanomami dá título a um dos onze capítulos de Brazuca negão e sebento, assim como "Glauber das mortes", "Dina Lévi-Strauss" ou "F(r)anny Deleuze". Capítulos escritos de modo críptico e enigmático, 
de que dou apenas um exemplo, quando entra em cena o Catatau, e em seguida a tradução-deglutição de Karai Mirim, que deita e rola, à página 50:

Bento faisant son Spinoza. Du grand théâtre! Quoi? Spinoza, un roi pédéraste habillé en femme, un Empereur de Carnaval? Un brésilien noir et crasseux seulement d'en avoir fini avec le vagin de maman et la fente des prostituées pour naître directement du cu de la Grand-Mère, "suie" du cu de la Substance-Nature? Voyons? Et le nouveau cogito espinosien: cogito ego-suie. Une lubie? Pas du tout. Rien de plus sérieux. Une affaire de sperme, de sang et de merde. Sans dégoût. Afro-polonais brésilien, le concrétiste Paulo Leminski ne connaît pas le dégoût, ne confond pas comme vous un trou avec l'absence de Dieu, car rien n'est meilleur qu'une bela cagada, une belle chiasse, un bel épandage de merde, et aucune merde n'est comparable à celle de l'Aimée... le véritable or du Brésil.

Bento pagando uma de Spinoza. Teatro do bom! Cuma? Spinoza, um rei pederasta vestido de mulher, um Imperador de Carnaval? Um brazuca negão e sebento só porque deixou de atravessar a vagina da mamãe e a racha das prostitutas para nascer diretamente do cu da Avó, 'fuligem' do cu da Substância-Natureza? Será? E o novo cogito espinosiano: cogito ergo pum! Um capricho? Porra nenhuma. Coisa serí́ssima. Uma questão de esperma, sangue e merda. Sem nojo. Afro-polonês brasileiro, o concretista Leminski não conhece o nojo e nem confunde, como vocês, um buraco com a ausência de Deus, porque não há nada melhor que uma bela cagada, uma bela caganeira, um belo jato de merda, e nenhuma merda é comparável à merda da pessoa Amada... o verdadeiro ouro do Brasil.

Neste ponto, o autor está citando - como sempre, sem entregar a fonte - o poema leminskiano "Merda e ouro", de Distraídos venceremos (1987). Haveria mil exemplos para desencavar deste pequeno grande texto canibal, além de mil e tantos comentários a fazer. Concluo esta resenha com só mais dois. Um: a deglutição do original faz o ensaio ganhar significados insuspeitados, graças ao português amazônico utilizado neste desserviço coletivo: a palavra catatau, abordada por Goddard em seus vários sentidos deste e do outro lado do Atlântico, é aproveitada pela tradução quando menos se espera; igualmente, o nome aportuguesado de Spinoza, Bento, reaparece aqui e ali antecedido pelo verbo ser no imperativo: "Sê Bento"; a bela sacada ganha o texto desde o título sebento e se espraia em demonstra- 
tivos como na "alucinação desse Bento de Amsterdã". Dois: o ensaio também é uma carta a Espinosa, ou melhor, uma carta ao Spinoza "falasha [imigrado], judeu e negão", que "assombra todo judeu em exílio através da interpelação do Outro" como visão de si mesmo, e que segue tim-tim por tim-tim os desmandamentos pau-brasileiros de Oswald de Andrade, autor do poema "Pero Vaz caminha", já que, em suma, para Pyaguachu, é preciso "furar, através da carapaça aristotélico-cartesiana da Ética, para dele nutrir o olho, o pau mulato da alucinação de Bento".

Recebido em: 31/08/2018

Aceito em: 19/01/2018 